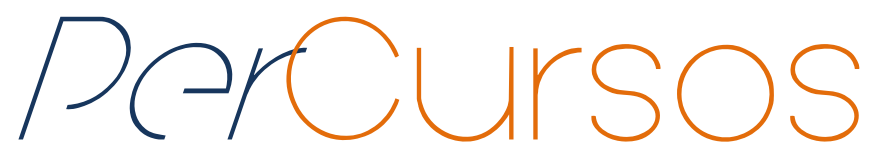

\title{
Los límites sociales de la migración ecuatoriana hacia Europa: un estudio de caso
}

\section{Resumen}

A la luz del proceso migratorio contemporáneo desde Ecuador hacia Europa, quiero mostrar en este artículo las rupturas, los cambios, las continuidades y las vinculaciones con el país de origen al interior del hecho migratorio por parte de los protagonistas y de su ambiente social. En este artículo quiero mostrar los cambios sociales tenidos en el lugar de origen - y que son amplificados través el mecanismo de las redes migratorias - que he estudiado en varios trabajos de campo desarrollados de la autora entre 2003 y 2010 en Ecuador, España, Italia y Francia. Me enfoco en mostrar como a una mayor capacidad económica - adquirida gracias a la migración, sea como protagonista, sea como familiar de migrante - corresponde, frecuentemente, a una nueva movilidad social y a un diferente sistema de valores relacionado con un diferente uso del dinero y de su poder simbólico.

Palabras clave: Migración Contemporánea; Remesas; Cambio Social; País de origen.

\section{Para citar este artigo:}

PAGNOTTA, Chiara. Los limites sociales de la migración ecuatoriana hacia Europa: un estúdio de caso. Revista PerCursos. Florianópolis, v. 15, n.28, p. 42- 62. jan./jun. 2014. 
Os limites sociais da migração equatoriana à Europa: um estudo de caso

\begin{abstract}
Resumo
À luz do processo migratório contemporâneo do Equador à Europa, quero mostrar neste artigo as rupturas, as mudanças, as continuidades e os vínculos com o país de origem dentro do contexto migratório por parte dos protagonistas e seu ambiente social. Neste artigo, pretendo expor as mudanças sociais obtidas no lugar de origem - e que são ampliadas por meio do mecanismo das redes migratória - que estudei em vários trabalhos de campo desenvolvidos pela autora entre 2003 e 2010 no Equador, na Espanha, na Itália e na França. Foco-me em mostrar como uma maior capacidade econômica - adquirida graças à migração, seja como protagonista, seja como familiar de migrante - corresponde, frequentemente, a uma nova mobilidade social e a um diferente uso do dinheiro e seu poder simbólico.
\end{abstract}

Palavras-chave: migração contemporânea; remessas; mudança social; país de origem.

\section{The social limits of Ecuadorian migration to Europe: a case study}

\begin{abstract}
As a consequence of the contemporary migration process from Ecuador to Europe, I want to show in this article some breaks, changes, continuities and linkages with the State of origin of the migrants and their social environment. This article concerns the social changes accounted in the place of origin - and amplified through the mechanism of migration networks - that I have studied between 2003 and 20010 in Ecuador, Spain, Italy and France. My attention is particularly directed towards social change taken in the place of origin and are amplified through the mechanism of migration networks between both sides of the ocean. I focus on showing how to greater economic capacity - gained through migration, either as an actor, either as migrant family corresponds frequently to a new social mobility and a different system of values associated with a different use of money and of its symbolic power.
\end{abstract}

Keywords: contemporary migration; remittances; social change; country of origin. 


\section{Introducción}

Entre las características prominentes de la época contemporánea que Stephen Castel y Mark Miller llaman “Era de la migración” se encuentra el crecimiento de los flujos que cruzan las fronteras geográficas, refiriéndose a ellos en sentido amplio, incluyendo las inversiones económicas, las remesas, el comercio, los productos culturales, las ideas, las personas y las redes transnacionales (CASTLES, MILLER, 2004). Estableciendo una correlación entre temporada de emigración y destino, podemos notar como alrededor de 10 millones de personas han viajado en la década de los noventa, siendo Estados Unidos el primer país a recibir ese flujo; con el transcurrir del tiempo los lugares de llegada se han diferenciados y Europa empieza a transformarse en una meta significativa, específicamente España para los latinoamericanos y Holanda e Inglaterra para los caribeños. Los expertos explican la orientación de los flujos latinoamericanos hacia Europa por algunas razones como: la entrada más difícil en Estados Unidos después del 11 septiembre 2001, la militarización de las fronteras mexicanas (al norte y al sur), la situación de pobreza en los países de origen, la solicitud europea de mano de obra extranjera para algunos sectores específicos, y las cadenas migratorias que contribuyen a garantizar una continuidad al flujo incluso en ausencia de un equilibrio entre costes y beneficios (YÉPEZ, BACH, 2007/2008). Para el caso europeo, a principios de los noventa hubo un pequeño aumento de los flujos procedentes de Ecuador, Colombia y Bolivia, y que se fueron consolidando a partir del 2000 cuando la crisis económica en los países de origen (Ecuador 1999, Bolivia 2003), ocasionó una expatriación masiva hacia los lugares donde anteriormente sus compatriotas habían emigrado y establecido su residencia. Los inmigrantes de los años noventa fueron la cabeza de puente de la cadena migratoria para los que dejaron el país de origen a principio del siglo XXI.

A partir de un estudio de caso conducido entre 2003 y 2007 en Génova (Italia), Madrid (España) y los lugares de partidas de los inmigrantes en Ecuador, mostraré como debido al crecimiento del poder económico obtenido con la migración, sobre los migrantes pesa la sospecha de parte del entorno social en el país de origen de ser bendecidos sociales, tránsfugos y por ende sufren de una forma de rechazo y de 
estigmatización. ${ }^{1}$ Por fin, enfocando el análisis de un punto de vista microsocial, se desprende como, por efecto de la emigración y de las remesa, se ha formado un nuevo criterio de determinación del status social: la adquisición de bienes materiales que determinan una nueva forma de estratificación. Muy frecuentemente el envío y la utilización de bienes de importación representa un modo de convertir el capital económico en capital político, social, cultural y simbólico (BOURDIEU, 1979).

A nivel metodológico he trabajado principalmente con las historias de vida de los migrantes y sus familiares cuyo origen era principalmente rural ${ }^{2}$. La adopción de una perspectiva de investigación basada en la subjetividad de los migrantes ecuatorianos permite ver cómo las formas de vida de los protagonistas se construyen socialmente con el paso del tiempo, atadas a un contexto específico, y no son el resultado de una supuesta identidad cultural preexistente.

\section{Los lugares de vida}

La palabra tránsfugo remite idealmente a una traición, ya que hace referencia a la idea de que la persona ha mutado sus propios valores de referencia, diferenciándolos de los de su origen. Las metas económicas que los ecuatorianos alcanzan en Europa no son posibles con la permanencia en el lugar de origen, y eso los convierte en bendecidos sociales, ya que acceden a un poder adquisitivo y a un bienestar superior del que podrían tener en su patria. Terrail (1984) analiza, en el caso francés, la trayectoria de jóvenes procedentes de familias obreras que acceden a profesiones intelectuales, pero debido a sus orígenes siguen siendo déracinés; el autor considera que ellos son tránsfugos sociales en la medida en que han adquirido elementos del nuevo entorno cultural y ha empezado un cambio con respecto al estatus social de pertenencia.

\footnotetext{
${ }^{1}$ Son considerados tránsfugos los individuos que han incorporado las dinámicas típicas de un determinado universo social y que por circunstancias particulares se ven obligados a vivir en otro (Boudieu, 1989).

${ }^{2}$ Más específicamente he recogido 30 historias de vida, de hombres y mujeres inmigrantes, mestizos e indígenas en los diferentes lugares supra mencionados y los testimonios de sus familiares. Mismo si los testimonios vivían en Guayaquil o Cuenca, los padres eran originarios del campo y esto se denota viendo la tipología de las historias de vida.
} 
A través de la red migratoria entre Génova y Guayaquil ${ }^{3}$, se ha vuelto posible que Lorena y su abuela - migrantes ecuatorianas cuyos testimonios he recogido primero en Génova y luego en Guayaquil cuando las dos regresaron a vivir en el país andino - vivan en una casa de dos pisos ubicada en el suburbio Oeste de Guayaquil y de propiedad de la madre, Soledad, ecuatoriana y residente en Italia. El barrio surgió, a principios del siglo XX, a raíz del fenómeno de ocupación de las tierras de haciendas situadas en los márgenes de la ciudad y, actualmente está incluido en la red urbana. Antes de la migración los padres de Soledad vivían en la casa de al lado de su propiedad. Cuando realicé el estudio de campo, la planta baja estaba arrendada a otra familia. A pesar de que Soledad es propietaria de dos casas en Ecuador, motivada por su hija, invirtió el dinero ganado en Génova para la compra de otra casa fuera de la ciudad, una casa estilo condominio, en un complejo residencial cerrado. Una elección que se inscribe en el fenómeno de huida del centro urbano por parte de las clases sociales acomodadas que se trasladan hacia los suburbios y ciudadelas protegidas: la gated communities (RIO, 2000; DAVIS, 1990; MCKENZIE, 1994). Esto se confirma en las conversaciones informales con Lorena; ella insistió en que su madre comprara la casa en el condominio, porque siente que es un lugar donde estarán seguras, lejanas de los peligros de la ciudad. Al respecto, es interesante observar la diferencia absoluta entre los dos mundos en que vive Soledad. Mientras en Génova Soledad vive en una zona periférica considerada peligrosa, porque está poblada en gran número por inmigrados latinoamericanos; ${ }^{4}$ en Ecuador irá a vivir con su familia en un barrio "seguro" típico de las clases sociales acomodadas. En Italia la nacionalidad de las testigos es un factor que genera inseguridad, mientras que en el país de origen son ellas las que necesitan seguridad ante los peligros del mundo externo a privatopia. Además, hay que destacar como Soledad, que en Italia trabaja en el cuidado de ancianos, en caso de un eventual regreso a Ecuador irá a vivir en un barrio de lujo, donde probablemente ella misma tendrá una empleada que cuidará su casa. Gracias al dinero de las remesas, la familia en Ecuador eleva su tenor de vida accediendo a consumos típicos de otra clase social. Es interesante señalar que a la pérdida de estatus social en Europa corresponde el acrecimiento en Ecuador, gracias al nuevo poder

Sobre la peligrosidad de las bandas latinoamericanas en Génova ver Queirolo Palmas y Torre (2005). 
económico adquirido con la migración internacional ${ }^{5}$. Una vez más encuentra confirmación el hecho de que el referente identitario, para algunas de las inmigradas en Europa, sigue siendo el Ecuador, ya que la migración hacia los países mediterráneos no ofrece un reconocimiento social ascendente, mientras en Ecuador las mismas mujeres se convierten en emigradas de éxito (economico). Llevando al extremo la paradoja que surge de la historia de vida de Soledad, se puede decir que pasa del "gueto" europeo para llegar a la "ciudadela" ecuatoriana. Es interesante observar como a la privatopia guayaquileña no se trasladan únicamente las familias tradicionalmente acomodadas, sino también los migrantes enriquecidos ${ }^{6}$. Al respecto, es útil introducir la noción de consumo cultural propuesta por Pierre Bourdieu (1979). Para el autor, el consumo de objetos sobrepasa la necesidad de satisfacer una exigencia material, mediante una específica tipología de consumo se accede a un determinado estatus; el consumo se convierte, por lo tanto, en una práctica social que simboliza, y en nuestro caso quiere simbolizar, la pertenencia a un grupo social específico.

Los cambios que la migración internacional aporta son considerables también en el entorno campesino. En la zona de la sierra central del Ecuador, en el campo, prevalecen las casas de adobe, mientras que en la zona sur están disminuyendo por efecto de la migración. En estos lugares el cambio arquitectónico iniciando en los años ochenta aumenta gracias a las remesas que no son invertidas en actividades agrícolas, sino en la construcción de casas (MARTÍNEZ, 2005). Las nuevas viviendas en estilo europeo o norteamericano son uno de los efectos más evidentes del envío de los migradólares (dinero procedente de las remesas de los migrantes). La construcción de casas de cemento con más de un piso en las áreas rurales, aunque invalida el sistema de reciprocidad andina, dinamiza la economía de la zona. Actualmente, la construcción de casas "estilo migrante" ya no ocurre mediante las prácticas de reciprocidad, sino bajo la modalidad de contratación de albañiles, lo que implica la introducción de dinero en los mercados locales

\footnotetext{
${ }^{5}$ El estatus social en Europa, marcado de la precariedad y de la inserción en los esclavón más bajo de la sociedad de acogida depende precisamente de la entrada en una tipología de trabajos de-cualificados y con una alta porcentaje de "negro" que transforma, por ende las trabajadoras migrantes en unas "sin derechos" establecido por medio de un contrato y también en "sin papeles" dependiendo que, por la normativa europea, los papeles son otorgado a los migrantes que tiene un contrato regular de empleo.

${ }^{6}$ Las calles internas al complexo residencial se llaman como las principales ciudad Europea y mis testimonios me contaron que eligieron ir a vivir en calle Roma a recuerdo de su migración hacia Italia.
} 
(PAGNOTTA, 2010). Las viviendas de los familiares de los migrantes se distinguen de las de los no migrantes por la imposibilidad que tienen los campesinos, que viven de la agricultura y de los sueldos locales, de ahorrar recursos que permitan construir una vivienda de cemento de más de un piso (HERRERA, 2005).

En las regiones de alto porcentaje migratorio los parientes de los migrantes pueden adquirir bienes, en particular inmuebles rústicos, terrenos y casas en la ciudad a cifras mucho más elevadas de quién no recibe remesas.

Con frecuencia, el migrante delega a los familiares en Ecuador la construcción de su casa, enviándoles una foto de las villas de clases acomodadas de las sociedades europeas o norteamericanas para que construyan en Ecuador una vivienda parecida (WALMSLEY, 2001).

Por ejemplo, la comunidad emigrada de Balzar (Guayas) hacia Cataluña, está planeando invertir las remesas en la construcción de viviendas en su lugar natal. Según el portavoz de la asociación, Alfredo Cedeño, la característica principal de estas casas será el estilo europeo: "Serán muy parecidas a las casas que podemos ver en Barcelona o en los pueblos de los alrededores. La construcción del proyecto habitacional cambiará la fisonomía de Balzar" (CEVALLOS, 2007). La construcción de casas de tipo urbano en pleno campo ecuatoriano, que representa una ostentación de lujo completamente desligada de la economía campesina, se convierte en una forma de mostrar el prestigio alcanzado con el éxito favorable de la migración (MARTíNEZ, 2005). Esto es particularmente evidente en las zonas rurales del Ecuador donde los mestizos e indígenas han sido históricamente excluidos de la gestión del poder local. Como me cuenta Mabel, una trabajadora social en Oyacoto, un barrio periférico de Quito:

Lo que yo veo, en estos barrios que estoy viendo muchas casas que se están haciendo, las mansiones en pleno campo. Mansiones no tiene sentido ahí esas casas (...) El otro día hacia un análisis con un muchacho del barrio, y él me decía porque construyen ahí en ese barrio, en su barrio, porque es un poco demostrar el que me fui y no en vano que me fui. Entonces vieron, fui y construí esta casa y volver. Es como la imagen que dan a su comunidad. 
CHP: ¿Y las casas que están construyendo son muy diferentes de las de antes de la migración?

Totalmente. Copian las mansiones que ven en donde viven. Ya vas a ver casas de dos pisos en medio del campo, inclusive dicen que en Loja en el sur van a ver casas con ascensor en el campo (MABEL, 2005). ${ }^{7}$

El incremento exponencial de las construcciones en la zona sur del país ha sido interpretado por las clases urbanas medias y acomodadas como una provocación al orden jerárquico y a los cánones estéticos (HERRERA, MARTíNEZ, 2002). Al respecto, dice Federico:

Todas las entrevistas citadas en este texto fueron conducida de la autora y hacen parte de su archivo privado. Todos los testimonios son indicado para uno pseudónimo. En itálico y precedido por CHP indico las preguntas de la autora. 


\section{El estilo migrante}

Una de las diferencias más importantes entre migración interna e internacional reside en el hecho de que la migración al extranjero acelera los cambios sociales más que una migración interna; las migraciones son, en gran parte, definitivas y se practican no para seguir viviendo al modo "tradicional" sino para acelerar los cambios en el sentido de la modernidad. En el caso que presento podemos ver como no se emigre para seguir siendo campesinos, se emigra para volverse ciudadanos, posiblemente acomodados.

Más allá de las evaluaciones estéticas, hay que considerar que la construcción de casas con ladrillo y mortero en la Sierra Ecuatoriana simboliza hoy en día el logro de un nivel de bienestar seguramente más elevado con respecto a la vida en las casas familiares campesinas en pasado construidas con adobe. Las familias migrantes campesinas, por ende, por efecto de las remesas, pueden así aspirar y aprovechar de un nivel de vida parecido al de las clases medias urbanas.

La mayor circulación de bienes en las comunidades locales crea un mecanismo de emulación, las viviendas se vuelven aún más lujosas, hasta convertirse en un símbolo de estatus (WALMSLEY, 2001). Es lo que se Ilama síndrome migratorio. Otro de los efectos del síndrome es el progresivo abandono de los campos en favor de una migración que busca la adquisición del poder económico como obtuvieron los primeros migrantes. Contemporáneamente, se pueden en la ciudad distinguir lugares y símbolos específicos reservados a los migrantes y sus familias: “casa migrante, estilo migrante, traje migrante (...) que develan jerarquías clasistas y revelan como la movilidad social producida por la migración no está legitimada dentro de la cultura y de las élites locales" (HERRERA, 2005, p. 220-224).

Parece que en Ecuador, por efecto de la migración y de las remesas se ha planteado un nuevo criterio de determinación del status social dentro de la comunidad de partida: la adquisición de productos materiales por parte de los familiares del migrante que determina una nueva ubicación no reconocida como legítima por las antiguas jerarquías sociales. El proceso de enriquecimiento de parte de los sectores medio-bajos de la sociedad es, por lo tanto, estigmatizado como una inversión del orden social ya que 
fue conseguido de una manera ajena y lejos del grupo de origen. Ne se trata en este caso del enriquecimiento en sí, obtenido quedando al interior del grupo de origen, más bien del enriquecimiento obtenido gracias a la migración internacional y el alejamiento de la jerarquía sociales de partida. En síntesis, lo que es duramente aceptado es el cambio de orden económico, y por ende social, que el proceso migratorio conlleva en el lugar de origen.

En un caso similar, Sayad (2002) analiza la función espejo de la inmigración, para la cual hablar de migración significa hacer referencia a la sociedad y a su organización. Además él observa que: "Es necesario recordar que toda emigración es ruptura, ruptura con un territorio y, por ende, con una población, un orden social, económico, político, cultural y moral. Pero, causa de ruptura, la emigración misma es el producto de una ruptura fundamental: es necesario que desaparezcan todos los marcos que aseguraban la cohesión de la sociedad para que la emigración pueda aparecer y perpetrarse". (SAYAD, 2002, p. 123)

En este sentido la migración ecuatoriana emerge como una ruptura con el orden vigente respecto de las dinámicas de clase e étnicas. Las jerarquías sociales preexistentes mutan y son creadas otras nuevas al adquirir los medios para hacerlo (el dinero proveniente de las remesas enviadas al país de origen por los migrantes), más allá de las normas sociales admitidas. En otras palabras, el cambio es percibido como provocado por un factor externo que no puede ser reconducido a dinámicas locales internas y esto hace que los nuevos hábitos ligados a un diferente uso del dinero y a distintas modalidades de consumo sean estigmatizados, y eso se hace en manera aun mas fuerte entre unos grupos indígenas. Menudo el envío de dinero permite acceder a espacios y modalidades de consumo consideradas ajenas y calificadas como materialistas y superficiales porque persiguen únicamente el lujo. El cambio que la migración conlleva, pero no siempre es socialmente reconocido y aceptado, ya que parece que las viejas estructuras jerárquicas continúen desenando el orden social. A propósito agrego las palabras de Álvaro 
(Saraguro) $)^{8}$, que expresa una desaprobación moral hacia quien ha "hecho suerte" emigrando:

En principio, quizás la mayoría de la gente ha utilizado para sus vanidades personales. Es más para ropa, es más para comer bien, es más para tener un auto. Por ejemplo la gente que viene de allá de España, llega aquí y el primer día ya está con su auto ¡Ya está con su auto! Aunque no tenga casa, aunque no tenga un negocio o no tenga otras cosas más. Primer día y ¡está con su auto! (ÁLVARO, 2006).

Desde Saraguro, Lucas, cuyos hermanos han emigrado a España, relata lo que sucede en el caso de los migrantes de vuelta:

Cuando a veces, por ejemplo la costumbre aquí de las comunidades de organizar fiestas, eventos grandes en las comunidades, entonces los familiares de acá los [al familiar emigrado] llaman y dicen: "Mira estamos de fiesta, ustedes que tienen dinero ¿Por qué no nos envían? Reúnanse todos los que son de aquí, de la comunidad allá, y pues hagan una colecta y envíennos". Y han enviado dinero, a veces 500 dólares, 1000 dólares, envían hacia acá ¿Para qué? Para que sean gastados exclusivamente en esas fiestas por ejemplo, o para hacer alguna obra social también que en algunos casos han aportado. $Y$ eso nos consta, al menos me consta que muchas comunidades se hace de esa forma, incluso mis propios familiares han hecho eso.

¿Pero refuerzan la posibilidad de hacer fiestas comunitarias más grandes?

Sí, sí. Pero aquí, iniciativas que se hagan aquí, entonces se les pide que nos envíen y nos envían (ÁLVARO, 2006).

Además, considerando que los familiares dependen del envío de remesas para acceder a un mejor nivel de vida, los migrantes se transforman en el centro articulador de la economía. Al respecto presento el relato de María, una mujer emigrada en Génova9:

Con el dinero ayudo económicamente a mi hermana, también. Porque su marido no trabaja, y ella es secretaria y gana ciento cincuenta dólares al

Saraguro es una localidad geográfica en la sierra sur del Ecuador y también el grupo indígena que habita la dicha localidad.

9 Génova es uno de los principales destino de la migración ecuatoriana hacia Italia. 
mes. Por esto su hija quiere venir a Italia a vivir conmigo. Bueno, porque yo le compro todo lo que quiere, pero yo le dije: "no ahora" porque no tengo una casa, vivo con el viejito donde trabajo, ¿cómo puedo acogerla conmigo? Ves, su mamá le puede comprar pocas cosas porque su marido juega todo el día al fútbol, y luego está demasiado cansado para trabajar, así que el dinero es poco; por eso yo los ayudo (MARÍA, 2002).

María es vista como quien puede "consentir" a la sobrina con el dinero de las remesas; la madre, o en general, los familiares en Ecuador no pueden hacerlo a causa de los escasos ingresos. En esta dinámica, ella resulta ser la persona "exitosa" a los ojos de la sobrina, ya que puede permitirle las compras que ella desea.

A propósito de la imagen del migrante que se tiene en el país de origen, Federico, trabajador social, relata cómo es percibida en Ecuador la nueva clase social fruto de la migración. Según su opinión, se produce un conflicto de poder entre la vieja élite y los familiares de los migrantes, ya que los primeros no reconocen el estatus de los nuevos ricos:

Los viejos ricos son los que históricamente tenían dinero y tenían apellido y generalmente en Cuenca se han llevado por el apellido de la persona, supuestamente por el linaje, la casta social (...) Ese es el rico tradicional. El nuevo rico es alguien que ahora tiene dinero pero no ha tenido el linaje o la casta social (...) Siempre le van a decir (...) Generalmente hay un término que utilizan acá mucho, no se tal vez es muy fuerte (...) Generalmente saben decir es un burro con plata (...) O sea (...) No está a nuestro nivel (...) Veras, uno de los ejemplos de estos, entre los nuevos ricos y los ricos fue el Colegio [nombre del Colegio] hace ya cuatro años hubo elecciones del consejo estudiantil, en el Colegio [nombre del Colegio] se educan o se educaban (no se ahora cómo estará la dinámica) los hijos de la sociedad y empezaron a tener acceso los hijos de migrantes al centro educativo, por su capacidad económica. En las elecciones del consejo estudiantil hubo una lista (nosotros le decimos con los niños bien) y en la otra lista eran hijos de migrantes y por primera ocasión ganaron los hijos de migrantes las elecciones. Se dio una balacera por la noche en uno de los festejos por haber ganado (FEDERICO, 2006).

La migración crea lo que Sayad (2002) llama "astucia social" y que es constantemente denunciada, en Ecuador, como un "fraude". Se trata del hecho que la migración ha contribuido a modificar las fronteras que separaban los grupos sociales, 
ofreciendo a los migrantes y a sus familias los medios para una ascensión social considerada ilícita porque se ha conseguido con modalidades externas a la jerarquía nacional. En efecto, las élites dominantes estigmatizan fuertemente esta clase social de nuevos ricos, y no la reconocen como plenamente legítima. Surge claramente de los extractos de los testimonios que las ganancias procedentes de la migración aumentan el poder económico, pero no crean permeabilidad social.

Peggy Levit (2001) describe un fenómeno parecido; se refiere a las "remesas sociales" que consisten en el flujo de ideas, conductas e identidades de referencia que desde la sociedad de llegada viajan hacia la de origen y transforman las estructuras normativas, las prácticas y el capital social de los grupos de salida como consecuencia de la migración. Según mis testimonios, el país de llegada cambia la mentalidad del migrante y de sus familiares gracias a la potencia del dinero:

CHP: !Y entonces se puede decir que las relaciones son más "monetarizadas" que antes, ¿no?

Sí. Evidentemente es mucho más monetarizado en este caso. El migrante ya no piensa en procesos de construcción social, organizativo, político. Yo tengo un cuñado en los Estados Unidos, un amigo mío se fue hace un mes, algo así, para un evento y se ha encontrado con él, y él me comenta este está cambiadísimo, el ya no piensa en organización, ya no piensa en la familia, en que hay que trabajar por la comunidad ni nada, lo que él dice es que hay que trabajar, hay que tener dinero, hay que hacer microempresas o empresas para seguir obteniendo más capitales, entonces está pensando siempre en eso y la mente te va cambiando. El entorno social en donde está viviendo la familia, en este caso, la persona migrante, pues, hace que se cambie automáticamente (ÁLVARO, 2006).

También las relaciones familiares en Ecuador son percibida de los testimonios como cambiantes. Por ejemplo, según un testimonio saraguro el cuidado de los hijos de los emigrantes por parte de los familiares se transforma en una relación económica:

Bueno, cuando se quedan niños, pues él se queda con los familiares más cercanos, en este caso abuelas. Generalmente se queda con la mujer, abuelas o tías o tíos, familiares que se quedan a cargo de, en este caso la persona, aunque también hay problemas. Han surgido problemas en ese 
entorno, hay a veces que los papas le dejan por ejemplo, le dejan conmigo, yo soy tío de los chicos, me quedo con los niños, el papa le deja (...) Pero en cambio los niños no quieren estar con él, sino que quieren estar con el abuelo por ejemplo, entonces ahí hay un desquite, un "tire y jala" decimos nosotros entre dos partes y en ese momentos se han producido algunos inconvenientes también aquí, peleas internas. Primero porque también viene una remesa de pago por ejemplo a la familia que está cuidando y que les manda dinero en efectivo, mensual, trimestral, no se cada qué periodo, entonces ellos administran y tienen la posibilidad de administrar y también una parte para la familia que está cuidando, entonces hay intereses por ese lado, también se han creado y eso ha generado problemas en muchas, en muchas familias hasta aquí [en Saraguro] por ejemplo (ÁLVARO, 2006).

Como los migrantes mestizos, los Saraguro en España aparecen marcados por conflictos internos y nuevas relaciones de poder surgidas con la migración. A propósito, Lucas reporta lo que sus familiares le relatan desde Murcia:

Ellos que han dicho hay una discriminación, hay un racismo de los mismos compañeros de aquí.

CHP: ¿No de españoles?

No. De españoles no conozco, no me ha dicho nada, pero de los mismo compañeros [me han dicho] que hay un maltrato, hay un individualismo de lo que aquí no existe, no se ve.

CHP: O sea ¿no se ayudan entre ellos? ¿Compañeros del pueblo o compañeros de aquí?

De aquí, son los de siempre, compañeros indígenas, los mismos compañeros indígenas, o sea ahí prácticamente la mente se cambia (...) Ha cambiado (...) Entonces sufren porque no hay solidaridad, incluso en España ha habido (...) Lo último que me comentó mi suegro: en España había una posibilidad de apoyo para adquirir viviendas, entonces ¿qué hacían los compañeros saraguros?: como quiera adquirían vivienda, y para los nuevos que iban llegando subarrendaban sus casas pero a un precio elevadísimo y como los nuevos no saben. $O$ sea, la necesidad dónde hospedarse (...) Donde vivir es tan grande (...) Entonces a lo que encuentren (...) Entonces los mismos saraguros con ese problema. Entonces justo España quiso construir un ejemplo de solidaridad de los compañeros saraguros allá y no se ha logrado, eso es un indicador terrible. Entonces ese es el sentir ahorita allá, entonces yo dije de repente: si hay una enfermedad ¿Cómo se ayudan? Yo le pregunto a mi suegro, y él dice que como hay algunos que ya adquirieron vehículos, tienen sus carros, sus coches, entonces ;que no! [No se ayudan] Pagaba, todo se pagaba. Aquí en cambio es diferente, aquí si yo tengo un carro, 
tenemos una emergencia por ahí de mis vecinos, en comunidad, yo no puedo cobrar porque para nosotros es antiético a un vecino cobrarle. Si algún día me dio una mano y yo cobrarle: ¡no! Eso es imposible aquí! Es imposible en las comunidades digamos, pero allá no, o sea, los mismos compañeros de aquí, a veces sentir la preocupación, problemita del alcohol, los mismos compañeros de aquí han instalado bares, porque son zonas lejanas un poco del centro, así dice mi suegro (...) Bar, locutorios telefónicos, envíos de dinero; los mismos compañeros saraguros tienen esas posibilidades y como explotan a los otros (LUCAS, 2006).

Lucas relata las modalidades de acción de la red migratoria indígena en España. Si dentro de los procesos migratorios las redes desarrollan un papel fundamental de apoyo y ayuda entre los connacionales inmigrados, no hay que olvidar que eso se resuelve, a menudo, con una remuneración económica, en base a la cual se paga a un inmigrado con mayor tiempo de estadía en el país para obtener la información y la ayuda necesaria. Aunque haya habido el intento por parte de algún saraguro de crear una estructura más igualitaria en España, esto no se logró. Parece no haber distinción entre las modalidades de acción de los saraguro y de los mestizos que emigran hacia España.

En el extracto de la entrevista puede apreciarse como para Lucas la migración tiene un efecto de corrupción sobre las formas de actuar y de pensar típicas de los saraguro y se deduce que, él tiene como referencia la idea de una primigenia identidad indígena igualitaria y solidaria ajena de lo que concierne "el mercado".

No me interesa aquí mostrar si las creencias de mis testimonios sean verdaderas o no, mas bien, me interesa entender el porqué se forma una visión dicotómica que ve de un lado las tradiciones indígenas como igualitaria e positivas y el mundo contemporáneo como negativo e monetarizado y como esa interpretación se convierta en hegemónica en el grupo social de mis testimonios. El historiador Edward Thompson, en su estudio sobre las clases populares inglesas (THOMPSON, 1971), introduce el concepto de economía moral para explicar cómo los campesinos, que a finales del siglo XVIII desafiaban a los terratenientes, se sentían legitimados al defender sus derechos y las costumbres tradicionales teniendo el consentimiento de gran parte de la población en sus actos. Por lo tanto, sus acciones, reflejaban un valor moral y social. Probablemente, también la estigmatización hacia los migrantes que encontramos en las comunidades indígenas 
saraguro responde a una dinámica parecida. La reprobación de la migración parece asumir el papel de respuesta a una transformación de las normas sociales compartidas por la comunidad.

Un caso que recuerda - por unos aspectos aquello ecuatoriano - es lo que describe Nathan Wachtel (1992). El autor en el texto Dioses y vampiros, Retorno a Chipaya muestra como la persona acusada de ser un kharisiris, un vampiro local que se nutre de la linfa vital o de la grasa de los habitantes del pueblo boliviano, sea en realidad un emigrante retornado a vivir en el país de origen luego de una temporada en Chile donde había logrado ganar un poder económico que estaba ahora intentando de invertir en el pueblo en termino de prestigio. El autor explica como en unos caso anteriores el kharisiris era un extranjero, rubio, un elemento externo al pueblo, y ahora en el caso estudiado, el elemento externo es representado más bien del ex emigrante ahora "adinerado". En ambos, representa la irrupción de la modernidad al interior del mundo andino "tradicional".

\section{Conclusión}

La migración internacional aparece como un terreno muy fértil para identificar las ambigüedades que presupone la construcción de una identidad y de sentimientos de pertenencia.

La actual emigración internacional ecuatoriana se caracteriza por la rapidez con la que se producen los cambios, por la amplificación de los efectos creados, por su carácter de masas y por la heterogeneidad de los sectores sociales que participan. En tanto fruto de los cambios que implica la migración, se está construyendo una nueva identidad que produce una nueva movilidad social y un diferente sistema de valores relacionado con un nuevo uso del dinero y de su poder simbólico. Por efecto de la emigración y de las remesas, se ha formado un nuevo criterio de determinación del status social: la adquisición de bienes materiales que determinan una nueva forma de estratificación. Muy frecuentemente el envío y la utilización de bienes de importación es un modo de 
reconvertir el capital económico en capital político, social, cultural y simbólico (BOURDIEU, 1979).

Además, el ambiente de origen aparece mutar bajos los efectos de las migraciones gracias al flujos de informaciones, dinero, ideas, cultura, modelos de vida del país de nueva instalación se dirige hacia lo de origen en el que permanece el grupo domestico del migrante. Un traslado físico (migración) de un lugar al otro aparece impulsar multíplices traslados diferentes y de diferente tipologías. Se trata en este caso de flujos dirigidos no solo en una única dirección, más bien hacia ambos contextos que se autoalimentan y influencian mutuamente exactamente por efecto de la circularidad y fluidez migratoria.

Según García Canclini (1989), los sujetos involucrados en la migración pueden desarrollar una cultura híbrida que transforma la pertenencia original sin destruirla. Se trata de una aculturación por la cual el contacto con un ambiente extranjero crea una serie de implicaciones. La cultura, en tanto componente de la sociedad, se encuentra en constante transformación y con ella se modifican los modos de pensar, adaptándose al nuevo contexto.

Contemporáneamente, en el caso ecuatoriano, los emigrantes son, a causa de su mayor poder económico, muchas veces considerados, en sentido negativo, como milagrosos sociales, como tránsfugos. Las metas sociales que los latinoamericanos alcanzan en el extranjero no serían posibles en caso de permanencia en el ambiente de origen y esto hace de ellos milagros sociales ya que tienen acceso a un poder adquisitivo y a un bienestar mayor que el que tenían en su patria y porque alcanzaron una meta a la que otros de su misma clase y nacionalidad difícilmente podrán acercarse (permaneciendo en su lugar de nacimiento).

Emerge claramente de los testimonios que las ganancias provenientes del extranjero aumentan el poder económico pero no crean permeabilidad social.

Volviendo al caso europeo se puede ver en todo caso, como la referencia identitaria del migrante, cualquiera sea la sua sigue vinculada a su país de origen porque en el país de arribo va a conformar la parte más baja de la sociedad, protagonizando un recorrido de movilidad social descendente (trabajo en negro, precariedad, etc.). Por este 
motivo es importante para el migrante obtener un reconocimiento del poder económico adquirido en la sociedad de origen y así demostrar que ha triunfado por medio de la migración.

\section{Referências}

BOUDIEU, Pierre. La Distinction : critique sociale du jugement. París: Éditions de Minuit, 1979.

BOUDIEU, Pierre. La noblesse d'état : grandes écoles et esprit de corps. París : Minuit, 1989.

CALDEIRA, Teresa Pires do Rio. Cidade de muros: crime, segregação e cidadania em São Paulo. São Paulo: Edsup, 2000.

CASTLES, Stephen; MILLER, Mark, La era de la migración movimientos internacionales de población en el mundo moderno. México: Miguel Ángel Porrua : UAZ, Cámara de Diputados LIX Legislatura, Fundación Colosio, Secretaría de Gobernación, Instituto Nacional de Migración, 2004.

CEVALLOS, Jaime. Balzareños en Cataluña impulsan plan de vivienda. El Universo, Quito, 29 de septiembre de 2007. Disponível em:

<http://www.eluniverso.com/2007/09/29/0001/626/29903BE810CA495680CC4FF26984082 o.html>.

DAVIS, Mike. City of quartz, excavating the future in Los Angeles. Londres: Vintage, 1990.

GARCIA CANCLINI, Nestor. Culturas híbridas. México: Grijalbo, 1989.

HERRERA, Gioconda; MARTÍNEZ, Alejandra. Género y migración en la región sur. Quito: FLACSO, 2002.

HERRERA, Gioconda. Dall'altra parte della riva: percezioni e pratiche fra i figli di migranti rimasti in Ecuador. In: QUEIROLO PALMAS, Luca; TORRE, Andrea (Orgs.). Il fantasma delle bande: Genova e i Latinos. Génova: Fratelli Frilli, 2005, p. 217-234.

LEVITT, Peggy. The Transnational Villagers. Berkley: University of California Press, 2001.

MARTÍNEZ, Luciano. Migración internacional y mercado de trabajo rural en Ecuador. In: HERRERA, Gioconda; CARRILLO, María Cristina; TORRES, Alicia (Orgs). La migración ecuatoriana, transnacionalismo, redes, identidades. Quito: FLACSO, 2005, p. 147-168.

MCKENZIE, Evan. Privatopia: Homeowner Associations and the Rise of Residential Private 
Governement. New Haven-Londres: Yale University Press, 1994.

PAGNOTTA, Chiara. Attraversando lo stagno:storie della migrazione ecuadoriana in Europa tra continuità e cambiamento (1997-2007). Roma: CISU, 2010.

PAGNOTTA, Chiara. La migración ecuatoriana a España e Italia: historias, memorias e identidades (1995-2007). Quito: Universidad Andina Editora, en prensa.

QUEIROLO PALMAS, Luca; TORRE, Andrea (Orgs.). Il fantasma delle bande: Genova ed i Latinos. Genova: Fratelli Frilli, 2005.

SAYAD, Abdemalek. La doppia assenza : alle illusioni dell'emigrato alle sofferenze dell'emigrato. Milano: Raffaello Cortina Editore, 2002.

TERRAIL, Jean-Pierre. De quelques histoires de transfuges. Cahiers du Laboratoire de Sociologie Anthropologique de l'Université de Caen. Caen: v. 2, p. 35-74, 1984.

THOMPSON, Edward. The moral economy of the english crowd in the 18th Century: past \& present. Oxford: n. 50, p. 76-136, 1971.

WACHTEL, Nathan. Dieux et vampires. Retour a Chipaya. París: Seuil, 1992.

WALMSLEY, Emily. Transformando los pueblos: la migración internacional y el impacto social a nivel comunitario. Ecuador Debate. Quito: n. 54, p. 155-174, 2001.

YEPEZ, Isabel, BACH, Amandine. Entre ici er là bas: quelle citoyenneté des migrant-e-s latino-américain-e-s en Europe? L'ordinaire Latino-américain. Toulouse: n.208-209,p. 11-27, $2007 / 2008$.

\section{Entrevistas citadas}

Entrevista a Álvaro, Saraguro, 21 septiembre 2006.

Entrevista a Federico, Cuenca, 19 septiembre 2006.

Entrevista a Lucas, Saraguro, 21 septiembre 2006.

Entrevista a Mabel, Oyacoto, 6 septiembre 2005.

Entrevista a María, Génova, 6 noviembre 2002. 
Recebido em: 21/02/2014 Aprovado em: 25/04/2013

Universidade do Estado de Santa Catarina - UDESC

Centro de Ciências Humanas e da Educação - FAED

Revista PerCursos

Volume 15 - Número 28 - Ano 2014 revistapercursos@gmail.com 